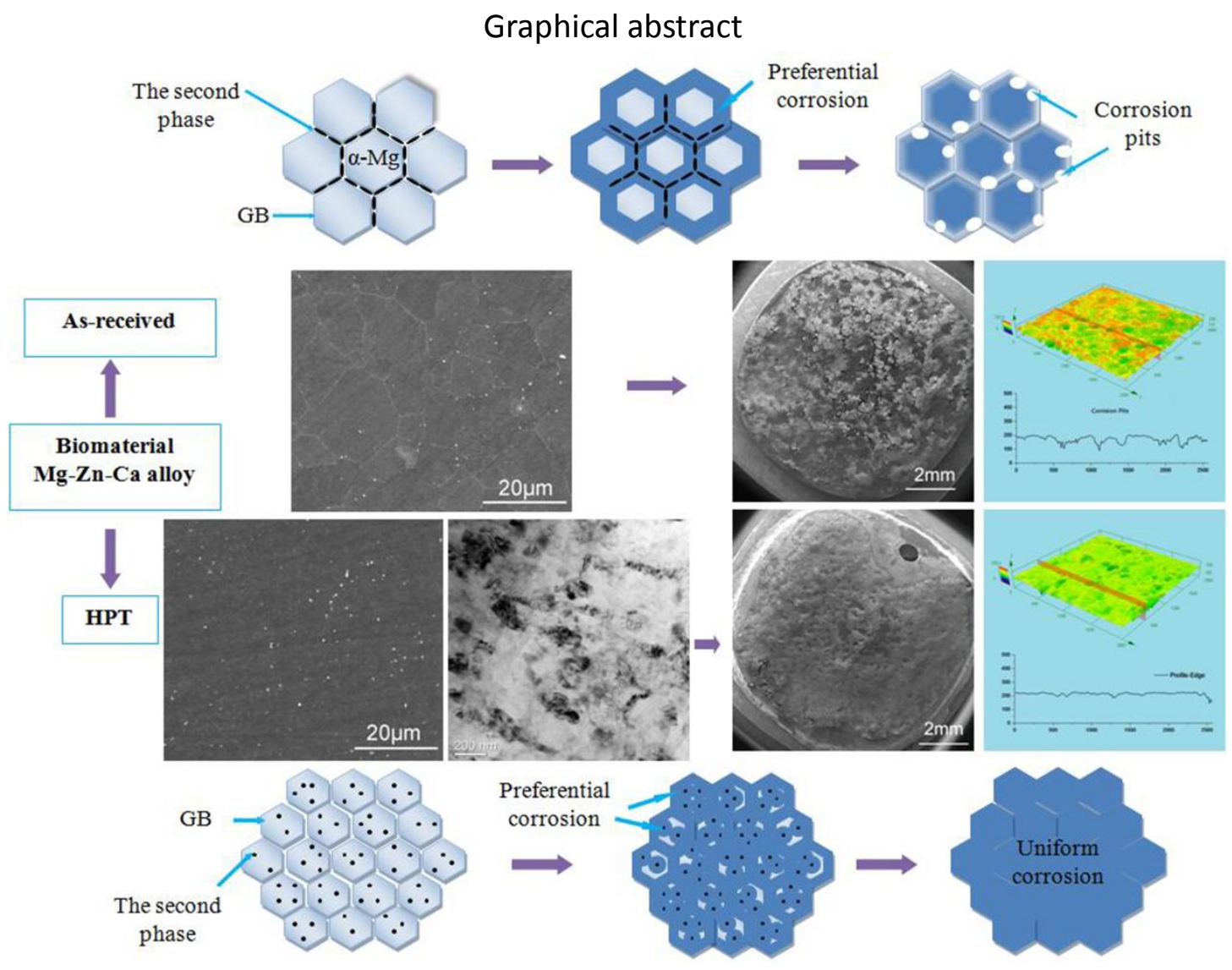




\title{
Microstructures and degradation mechanism in simulated body fluid of biomedical Mg-Zn-Ca alloy processed by high pressure torsion
}

\author{
C.Z.Zhang, S.J.Zhu*, L.G.Wang, R.M.Guo, G.C.Yue, S.K.Guan* \\ School of Materials Science and Engineering, Zhengzhou University, Zhengzhou 450002,PR China
}

\begin{abstract}
In this paper, biomedical $\mathrm{Mg}-\mathrm{Zn}-\mathrm{Ca}$ alloy was processed by high pressure torsion (HPT) up to a maximum of 5 revolutions at room temperature and 7.5GPa. The microstructures of as-received material and HPT material were studied, as well as the corrosion properties and degradation mechanism of the alloy immersed in simulation body fluid (SBF). It revealed that the average grain size of as-received material was $11 \mu \mathrm{m}$ and most of the second phases distributed along the grain boundaries. The corrosion pits formed near the grain boundaries where the corrosion rate was much faster than that of other areas. After HPT processing for 5 revolutions, not only the grain size was significantly refined to $130-150 \mathrm{~nm}$, but also the second phases distributed uniformly. These microstructural variations caused the entire surface of the alloy corroded almost at the same corrosion rate. The corrosion interface of the center region and the edge region presented the uniform and gentle profile curve without any obvious corrosion pits. The HPT material in SBF tended to degrade by uniform corrosion mode.
\end{abstract}

Key words: $\mathrm{Mg}-\mathrm{Zn}-\mathrm{Ca}$ alloy; High pressure torsion; Microstructure; Corrosion; Degradation

\section{Introduction.}

Magnesium alloy, with good biocompatibility and high load capacity, is popular in biomedical materials research field [1], [2] and [3]. The degradation characteristic of magnesium alloy can prevent second surgerical operation [4], [5] and [6]. Especially in clinical treatment of children's fractures, the indwelling time of bone plates needs to be strictly controlled due to the fast grow rate of children's bones [7]. The utilization of traditional non-degradable bone plates typically needs a second surgerical operation in a short period which tortures patients both physically and mentally. Therefore, it's necessary to develop a new type of magnesium alloy bone implant material which can provide a good mechanical stability in the initial stage of implantation, and then degrade in the expected time.

However, there are two obstacles hindering the wide application of magnesium alloys used as biomedical materials: firstly, the corrosion resistance is poor; secondly their mechanical properties still cannot satisfy the clinical requirements [8], [9] and [10]. In order to solve these two issues, researchers have tried several methods

\footnotetext{
${ }^{*}$ Corresponding author: Tel: +86 037167780051.

E-mail address: skguan@zzu.edu.cn (S.K.Guan)

${ }^{*}$ Corresponding author: Tel: +86037163887508.

E-mail address: sjzhu@zzu.edu.cn (S.J.Zhu)
} 
including surface modification, alloying, and plastic deformation etc. Surface modification can enhance the corrosion resistance but has no obvious improvement on mechanical properties [11], [12] and [13]. The additions of alloying elements usually lead to the formation of second phases which would cause local galvanic corrosion [14] and [15]. Plastic deformation can decrease the grain size and change the distribution of second phases to improve the mechanical and corrosion properties simultaneously [16] and [17]. However, the deformation capability of magnesium alloy is poor by conventional processing methods, due to its close-packed hexagonal (HCP) structure.

Severe plastic deformation (SPD) techniques, such as high pressure torsion (HPT) and equal channel angular pressing (ECAP), are used for producing ultra-fine grain (UFG) materials [18] and [19]. The metallic materials after SPD process show improved mechanical properties and corrosion resistance through refined grains and modulated distribution of the second phases [20], [21] and [22]. Compared with ECAP, the microstructure of HPT-treated samples is affected by the mould, and shear deformation of the samples will occur under the similar hydrostatic pressure [23] and [24]. The samples are difficult to rupture, even though the deformation amount is extremely large at room temperature (RT). Therefore, HPT technique is suitable for HCP magnesium alloy which is difficult to deform at RT [25] and [26]. In recent years, the diameter of HPT materials is increasing owing to the rapid development of HPT equipment. The samples treated by HPT technique can be made into miniature bone plates for children, which could be used in phalanx, phalanges, and skull, etc. With the further development of equipment, the HPT materials used as biomaterials will enlarge gradually in the future.

Nowadays, the research on HPT technology is mainly focused on increasing the strength and toughness of engineering alloy through grain refinement [27] and [28]. However, the research on microstructural evolution of biomedical magnesium alloy after HPT process is barely reported. Our preliminary study has showed that the corrosion resistance of HPT-treated magnesium alloy was improved in simulated body fluid (SBF), but the corrosion behavior and degradation mechanism were still unclear [29]. Accordingly, in this paper we selected HPT as the processing technique to prepare biomedical $\mathrm{Mg}-\mathrm{Zn}-\mathrm{Ca}$ alloy. Zinc and Calcium are selected as the alloying elements, because these two elements are non-toxic to human body and can improve the mechanical properties of the alloy. Besides, the element of Calcium could facilitate the new bone formation and accelerate bone growth rate [30]. Then we investigated the microstructure and the distribution of second phases. Moreover, the biological corrosion properties of as-received material and HPT material were evaluated by electrochemical measurement, immersion test and hydrogen evolution test. In addition, the degradation mechanism of the alloy in SBF was proposed.

\section{Materials and methods}

The experiment was conducted with a magnesium alloy having a chemical composition of $\mathrm{Mg}-2.0 \mathrm{wt} \% \mathrm{Zn}-0.24 \mathrm{wt} \% \mathrm{Ca}$. The alloy was prepared by semi-continuous casting. After homogenizing annealing, the alloy ingot was further 
extruded into a rod with a diameter of $12 \mathrm{~mm}$ at the temperature of $320^{\circ} \mathrm{C}$. The sample disks with a diameter of $10 \mathrm{~mm}$ and a thickness of $1.2 \mathrm{~mm}$ were cut from the extruded rod for HPT processing. Then the disks were polished to a final thickness of $0.82 \mathrm{~mm}$ and subjected to a quasi-constrained HPT facility [31]. Disks were placed in the depression between the two anvils, and then processed at RT by rotating the lower anvil at a constant speed of $0.5 \mathrm{rpm}$ under an applied pressure (P) of 7.5GPa. The samples were processed through total numbers of revolutions $(\mathrm{N})$ of 1,3 and 5 , respectively.

Scanning electronic microscope (SEM; Quanta-2000, FEI, USA), energy dispersive spectrometer (EDS), transmission electron microscope (TEM; Tecnai G2 F20 S-Twin, FEI, USA) and selected area electron diffraction (SAED) were used to observe the microstructure. Samples prepared for TEM were cut from the disks both at the center and at a distance of $3.5 \mathrm{~mm}$ from the center using diamond cutter. Bright field images were taken to determine the grain size and the distributions of second-phase at different locations of the alloy with TEM at a voltage of $200 \mathrm{kV}$. Electrochemical measurements were carried out on a chemical workstation (RST5200, Risetest, China) by using potentiodynamic polarization curve and electrochemical impedance spectroscopy (EIS) with a scan rate of $0.5 \mathrm{mV} / \mathrm{s}$. Both the as-extruded and HPT-treated samples were ground with $\mathrm{SiC}$ papers to 1000 grits and further polished to a mirror-like surface to ensure the consistence of the data obtained. Due to the limitations of the samples' size, all the samples were embedded into silicon rubber with only one side of $0.785 \mathrm{~cm}^{2}$ and exposed to the SBF solution having a same composition so that given in the Refs [32]. For immersion tests, each sample was kept in $35 \mathrm{~mL}$ SBF because at least $40 \mathrm{~mL}$ solution is needed for each $\mathrm{cm}^{2}$ of working surface according to the Refs [33]. The hydrogen evolution quantity was also recorded every $1 \mathrm{~h}$ and totally up to $48 \mathrm{~h}$ to evaluate the corrosion rate. All the tests were conducted at $37^{\circ} \mathrm{C}$ in a water bath. The morphology of corrosion product layer was analyzed using SEM after spray-gold treated. The samples were rinsed by chromic acid to remove the corrosion products, then the 3-D profile of corrosion interface was observed by confocal laser scanning microscope (CLSM; LEXT OLS4000, Olympus, Japan).

\section{Results and discussions}

\subsection{Microstructural observation}

The micrographs of the alloys before HPT process are shown in Fig.1(a).The as-received material has equiaxed grains with the grain size of $3 \sim 30 \mu \mathrm{m}$, and the average grain size is $11 \mu \mathrm{m}$ by statistical calculation. Most of the second phase particles distribute along the grain boundaries $(\mathrm{GBs})$ and a few of the particles distribute in grains. The sizes of the particles are $250 \sim 900 \mathrm{~nm}$ and the average size is 550nm. According to Refs [34], [35], [36], [37], [38] and [39], the second phases in grains and along GBs are $\mathrm{Ca}_{2} \mathrm{Mg}_{6} \mathrm{Zn}_{3}$ phases in $\mathrm{Mg}-\mathrm{Zn}-\mathrm{Ca}$ ternary alloys. As shown in Fig.1(b), the GBs are not observed in HPT material. It may be due to the ultra-fine grains so that the GBs are unable to be recognized through SEM. It will be observed and analyzed with TEM later. In addition, the second phase particles distribute 
dispersively and uniformly in matrix of HPT material. It is supposed that the improvement of the second phase distribution is caused by grain rotation and the rheological effect introduced by shear strain in the alloy during HPT process.
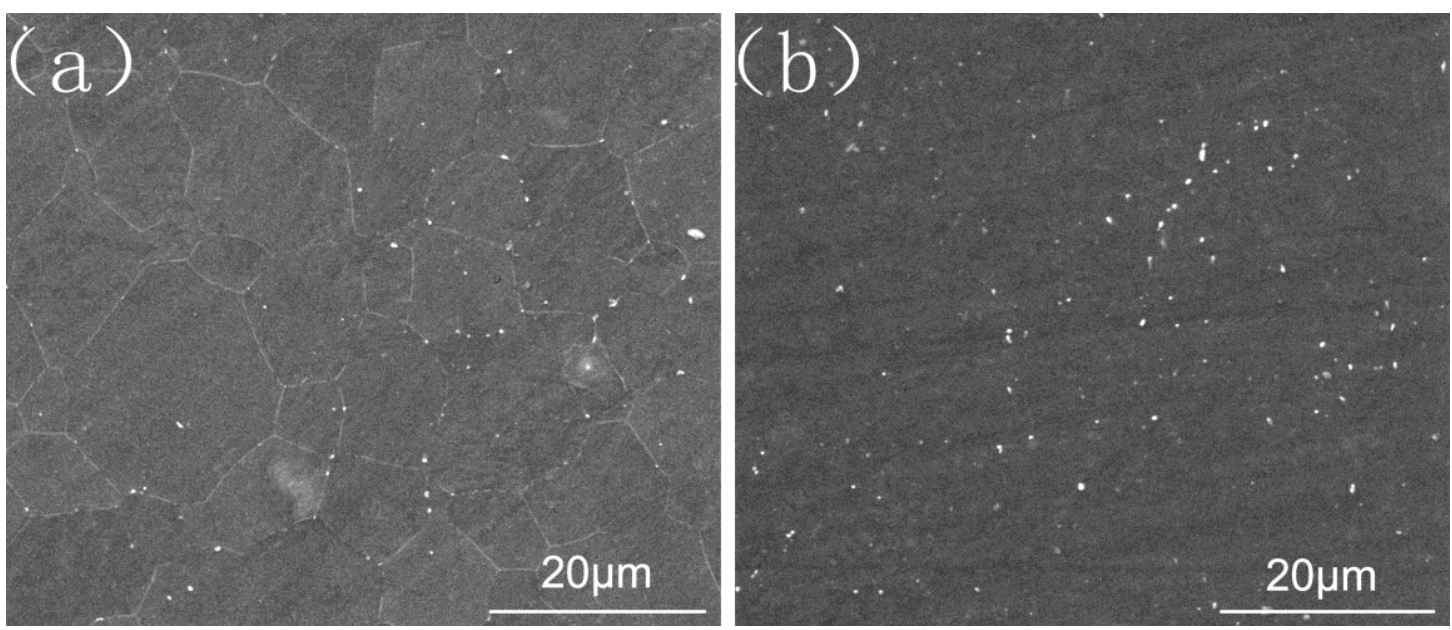

Fig.1. SEM micrographs of Mg-Zn-Ca alloy: (a) as-received material and (b) HPT material

In order to study the microstructural evolution of HPT material, the microstructure is further observed via TEM. Fig.2 (a) and (b) shows the TEM images at the center region and the edge region of HPT material after $\mathrm{N}=1$ revolution. The microstructures of the center region and the edge region have significant differences. At the center region of the alloy, the triple GB junction is observed. The GBs should be the original GBs before HPT, because the shear strain is very small in this region .The SAED pattern reveals that the grains have not been refined. However, at the edge region some fine grains can be found. The corresponding SAED result is found to be diffraction rings, indicating that the microstructure is refined as a result of larger shear strain and more severe plastic deformation. Fig.2 (c) and (d) show the TEM images of HPT material after $\mathrm{N}=3$ revolutions at the center region and the edge region. At the center region, the original GBs are not observed. It indicates that the original GBs have been destroyed with the increase of shear strain. The SAED pattern has a tendency to be diffraction rings rather than diffraction spots. At the edge region, more fine grains can be observed. It indicates that the degree of grain refinement is gradually increasing. The SAED pattern is remarkably diffraction ring. It can be observed that the spots in the diffraction ring are continuous and the diffraction ring appears tailing phenomena. The reason may be that the residual stress is relatively large in the sample [29]. When $\mathrm{N}$ increases to 5 revolutions, the degree of grain refinement reaches a saturation state with the increase of shear strain. The microstructures at the center region and the edge region are basically similar and consisted of fine grains. The SAED patterns at the center region and edge region show diffraction rings which are comprised of continuous spots. It is concluded that when the shear strain increases to a certain degree during HPT processing, the grains in the center region and edge region have been refined completely and the microstructures show an excellent homogeneity [40]. 

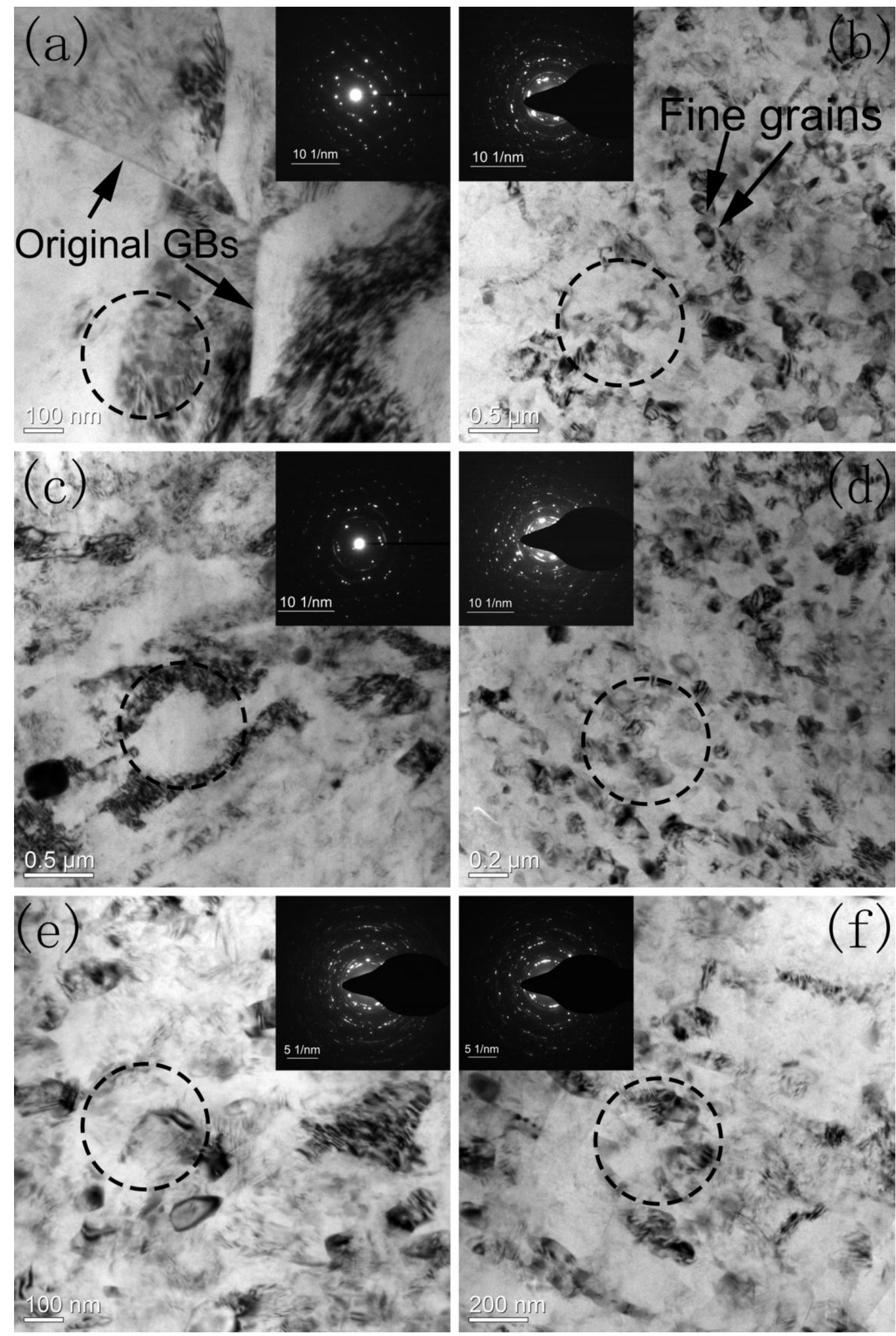

Fig.2. TEM micrographs of Mg-Zn-Ca alloy processed by HPT for (a) 1 revolution at the center region, (b) 1 revolution at the edge region,(c) 3 revolutions at the center region,(d) 3 revolutions at the edge,(e) 5 revolutions at the center region and (f) 5 revolutions at the edge region. 
After statistics and calculation of fine grains in TEM images, the grain size distribution and the average grain size of HPT material are obtained, as showed in Fig.3. For HPT material at $\mathrm{N}=1$ and 3 revolutions, the GBs in the center region are difficult to be distinguished, for this reason the evaluation of the grain size of these alloys is mainly concentrated on the edge region. The distribution of grain size of HPT material at $\mathrm{N}=1$ is dispersed. The distribution range is $20 \sim 400 \mathrm{~nm}$ and the average grain size of the sample is $\sim 151 \mathrm{~nm}$. When $\mathrm{N}$ increased to 3 revolutions, the average grain size $(\sim 134 \mathrm{~nm})$ decreased and the range of grain size distribution becomes narrow. However, the peak values of size distribution for $\mathrm{N}=1$ and $\mathrm{N}=3$ are the same. After 5 revolutions, the grain sizes of the center region and the edge region are $90 \sim 170 \mathrm{~nm}$ and 110 150nm respectively. Although the distribution ranges of grain size in the center region and the edge region have a little difference, the average grain sizes of the center region and the edge region are basically similar (about $\sim 135 \mathrm{~nm}$ ), and the microstructures are approximately homogenous. From the above, the bulk UFG Mg-Zn-Ca alloy with homogeneous microstructure and dispersive distribution of the second phase particles, is obtained at $\mathrm{N}=5$ revolutions.
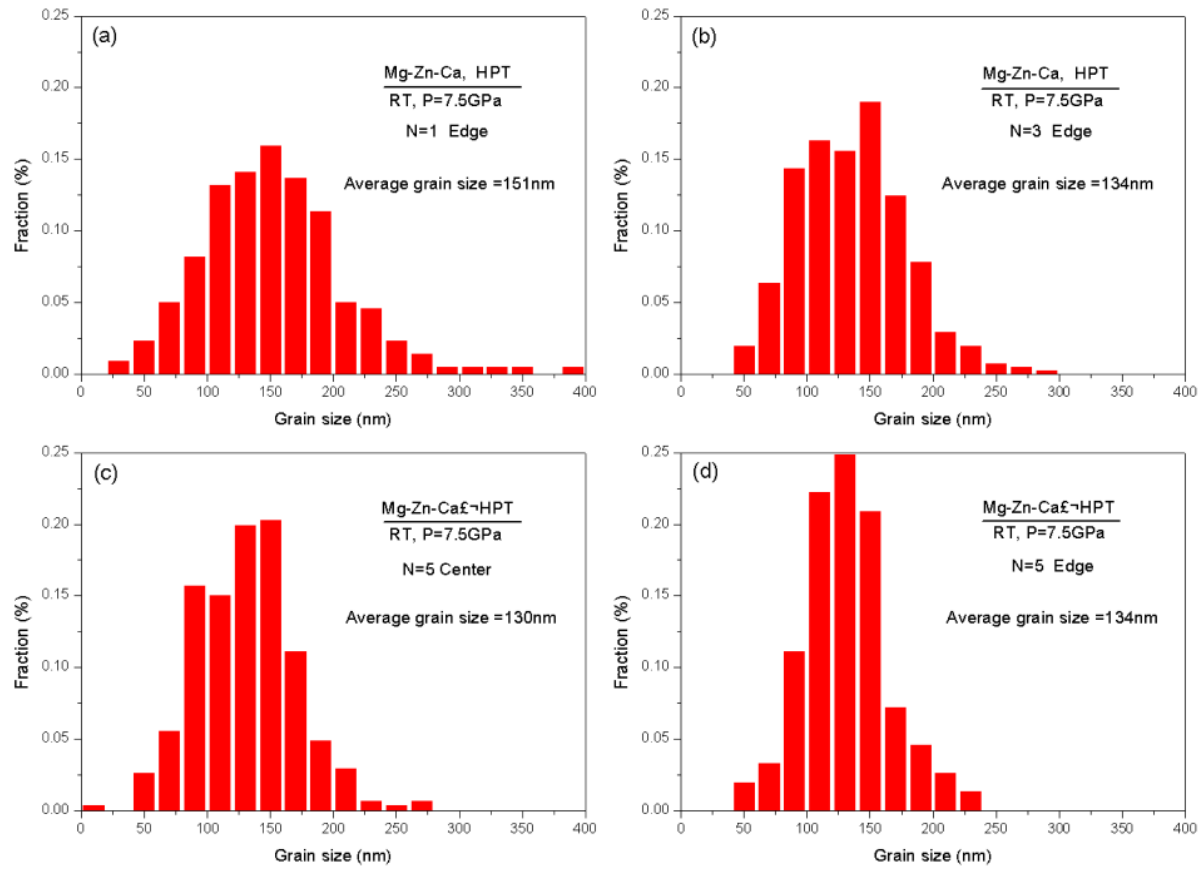

Fig.3. Histograms of the grain size distributions measured at (a) the edge region of the alloy after 1 revolution, (b) the edge region of the alloy after 3 revolutions,(c) the center region of the alloy after 5 revolutions and (d) the edge region of the alloy after 5 revolutions.

During HPT processing, the shear strain is small in the center region of samples, but large in the edge region. Accordingly, grains in the edge region are refined at first, afterward the refined region extends to the center gradually. Meanwhile, when the grain size decreases to a certain degree, it comes to a stable state. When the shear strain keeps increasing, the grains cannot be further refined. All of the center region is 
refined and reaches a stable state when $\mathrm{N}$ reaches a certain number. At this case, the grain sizes in both the center region and the edge region are almost similar, and the homogenous UFG materials are obtained. The main reason for grain refinement of HPT-treated magnesium alloy is the multiplication, movement and annihilation of dislocation. At the early stage of HPT processing, lots of dislocations proliferate in grain, and then diffuse and migrate under the action of shear strain. With the increase of shear strain, the dislocations are aggregated and tangled. When dislocation multiplication reaches a certain degree, dislocations begin to annihilate. As a result, a certain number of sub GBs have formed in the dislocation tangle zone, and further transform into new GBs. The original grain has been refined through segmentation of the new GBs. With the decrease of grain size, the density of GBs gradually increases. Because the GBs hinder the diffusion and migration of dislocations, the dislocation movement becomes more and more difficult. Even if the shear strain continued to increase, dislocations will not aggregate and annihilate. Therefore, there is no new GBs formed in the grains and segmented the grains. At this time, the grain refinement reaches a saturation level.

\subsection{Corrosion properties in SBF}

Fig.4 shows Hydrogen evolution data for as-received material and HPT material immersing in $\mathrm{SBF}$ at $37^{\circ} \mathrm{C}$. It is observed that the hydrogen evolution quantity of as-received material in SBF gradually increases with the time extension, but the speed becomes slower gradually. The hydrogen evolution quantity of HPT material decreases at a faster rate with the increase of $\mathrm{N}$. The improvement of corrosion resistance is the most significant, when the UFG Mg-Zn-Ca alloy with homogenous microstructure is produced after HPT at 5 revolutions. 


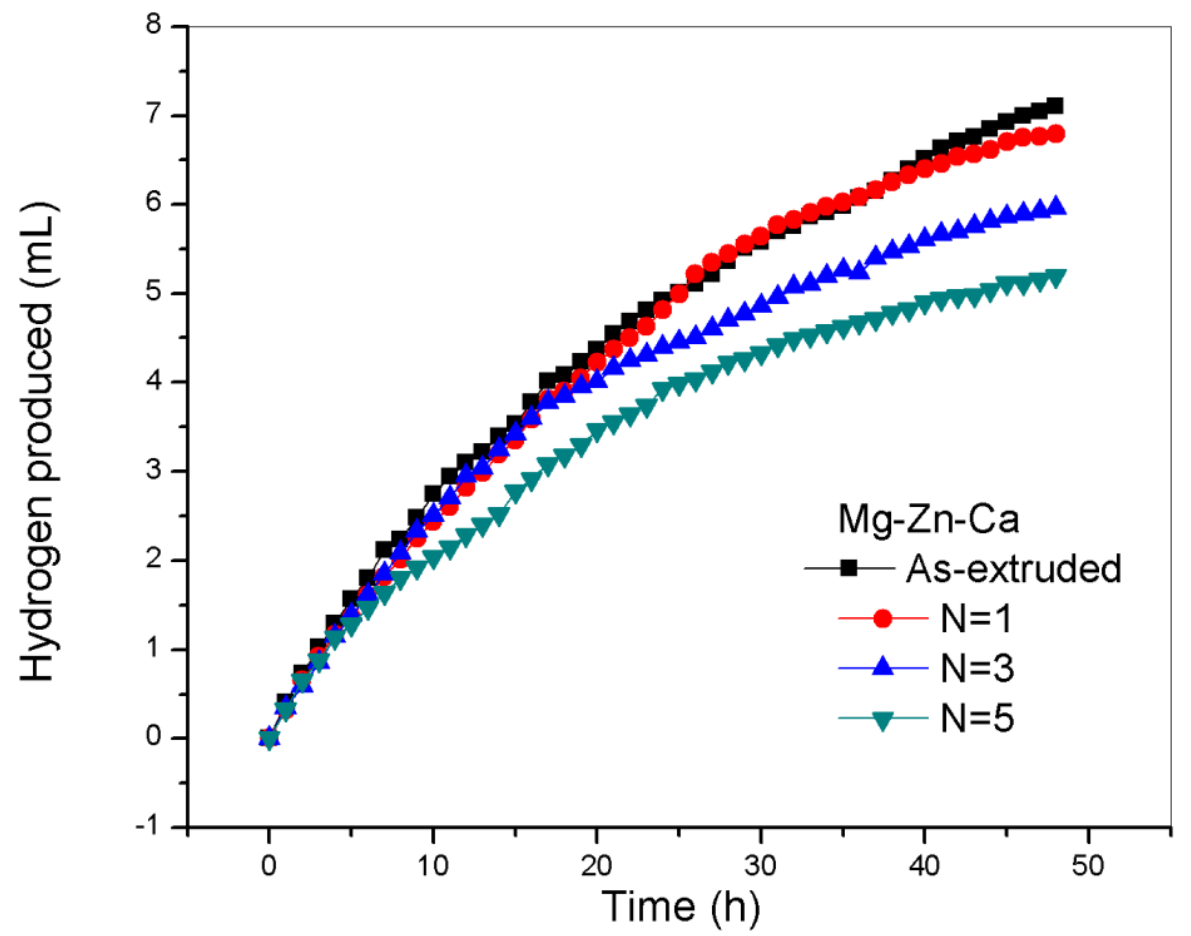

Fig.4. Hydrogen evolution data for as-received material and HPT material in SBF

Fig.5 (a) shows the potentiodynamic polarization curves of as-received material and HPT material. The self-corrosion potential shows an anodic shift in HPT material, and it is more positive with the increase of $\mathrm{N}$. Corrosion tendency of the alloy slows down after HPT process. Table 1 shows the self-corrosion density which is obtained from polarization curve fitting. Fig.5 (b) shows the EIS of as-received material and HPT material immersing in SBF. The high-frequency capacitive loop in EIS indicates the capacity of charge transfer. The radius of the high-frequency capacitive loop increases after HPT process. In addition, the capacity of charge transfer slows down obviously with the increase of $\mathrm{N}$. Meanwhile, the impedance value and capacity of retard corrosion gradually increases. As a result, the self-corrosion density of HPT material decreases and biological corrosion resistance is improved.

(a)

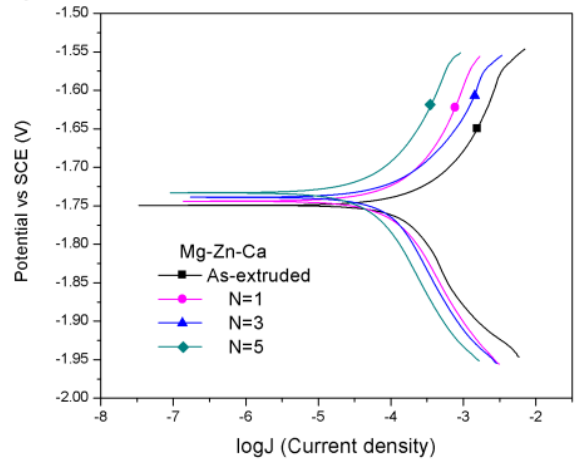

(b)

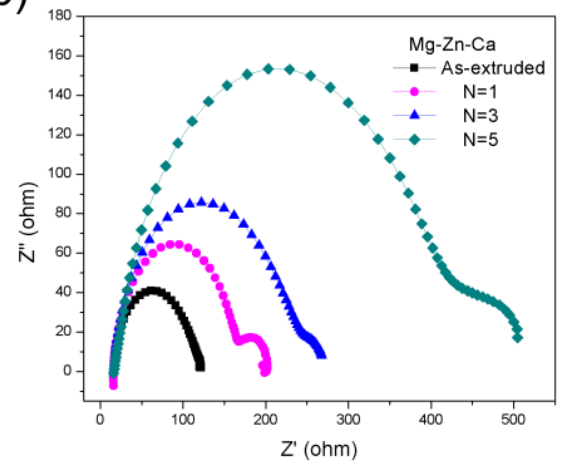


Fig.5. Electrochemical results of as-received material and HPT material immersed in SBF: (a) Polarization curve and (b) Nyquist plots of impedance spectra

Table 1 Electrochemical corrosion parameters of as-received material and HPT material obtained from polarization curves

\begin{tabular}{ccc}
\hline Sample & $\mathrm{E}_{\text {corr }} / \mathrm{V}$ & $\mathrm{I}_{\text {corr }} / \mathrm{A} \cdot \mathrm{cm}^{-2}$ \\
\hline $\mathrm{Mg}-\mathrm{Zn}-\mathrm{Ca}$ & -1.7494 & $1.719 \mathrm{E}-04$ \\
$\mathrm{~N}=1$ & -1.7439 & $5.237 \mathrm{E}-05$ \\
$\mathrm{~N}=3$ & -1.7392 & $4.156 \mathrm{E}-05$ \\
$\mathrm{~N}=5$ & -1.7323 & $2.187 \mathrm{E}-05$ \\
\hline
\end{tabular}

Fig.6 shows the corrosion morphology of as-received material and HPT material immersing in SBF at $37^{\circ} \mathrm{C}$ for $48 \mathrm{~h}$. Many cracks can be observed on the corrosion surface of as-received material and the corrosion products layer is loose. After HPT processed at $\mathrm{N}=1$ revolution, the corrosion layer is also loose and the large cracks appear when corrosion products accumulated. It can be known from the microstructure analyses that the microstructure characteristics are similar to as-received material because of the incomplete grain refinement. When $\mathrm{N}$ increases to 3 revolutions, second phase particles are dispersedly and uniformly distributed and some fine grains form as well at the edge region of the alloy. As a result, the corrosion products are uniform and compact. But at the center region of the alloy, most grains have not been refined. Therefore, the corrosion product layer is loose. After $\mathrm{N}=5$ revolutions, the loose degree of corrosion products layers at the center region become weak. The corrosion products layer at both center region and edge region is uniform and compact, which suggests that HPT material after 5 revolutions immersed in SBF degrade in the form of uniform corrosion. In conclusion, the cracks in HPT material almost disappeared. The corrosion products at the edge region change from loose to compact after HPT. What's more, the uniformity of corrosion morphology becomes higher with the increase of $\mathrm{N}$, although there is still a very small area of loose corrosion products at the center region of the alloy. 

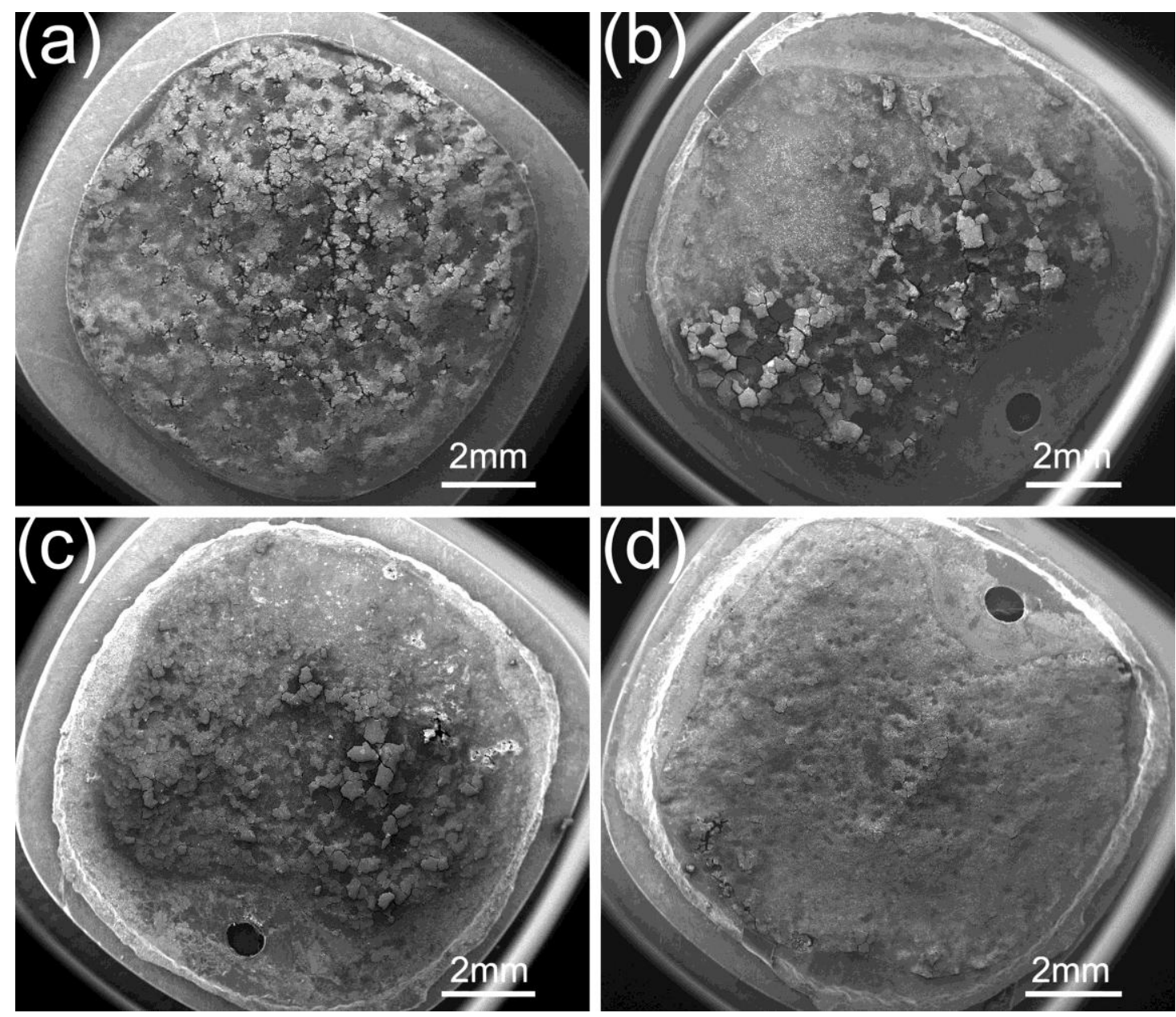

Fig.6. Corrosion morphology of Mg-Zn-Ca alloy immersed in SBF for 48h: (a) as-received material, (b) HPT material after 1 revolution, (b) HPT material after 3 revolutions and (c) HPT material after 5 revolutions.

When the corrosion products are removed by using chromic acid, 3-D profile of corrosion interface can be observed with CLSM. Fig.7 shows 3-D corrosion profile of as-received material. Many corrosion pits can be found. The corrosion preferentially occurs near the second phase particles which distribute along GBs. When the corrosion diffuses gradually and horizontally to interior of grain, it diffuses longitudinally a bit faster along GBs. Subsequently, the pitting corrosion is formed. Fig. 8 shows 3-D corrosion profile of HPT material without corrosion products. It should be noted that the colour scales in Fig. 8 are not the same. This is because that the highest and lowest points on the surface of these samples are different so the scanning ranges of the samples are also different, and the colour scales are set according to the scanning ranges. Therefore the colours of the samples are different in CLSM images, and corrosion resistance cannot be evaluated by comparing the colours. However, the number, size and depth of corrosion pits can be directly observed in the 3-D morphology of the sample surfaces. In addition, the profile curves can characterize the surface smoothness of the samples. Hence, corrosion resistance of the samples can be evaluated by corrosion pits and profile curves. Some deep corrosion pits have formed at the center region of alloy after HPT processed at $\mathrm{N}=1$ and 3 revolutions, but the corrosion interface at the edge region of alloy tends to be uniform. 
As shown in Fig.8 (e) and (f), the 3-D corrosion profile at the center and edge region of HPT material after 5 revolutions becomes smooth. There is no obvious deep corrosion pit. The profile curve gradually becomes gentle with the increase of $\mathrm{N}$, and the corrosion behavior tends to be uniform corrosion.

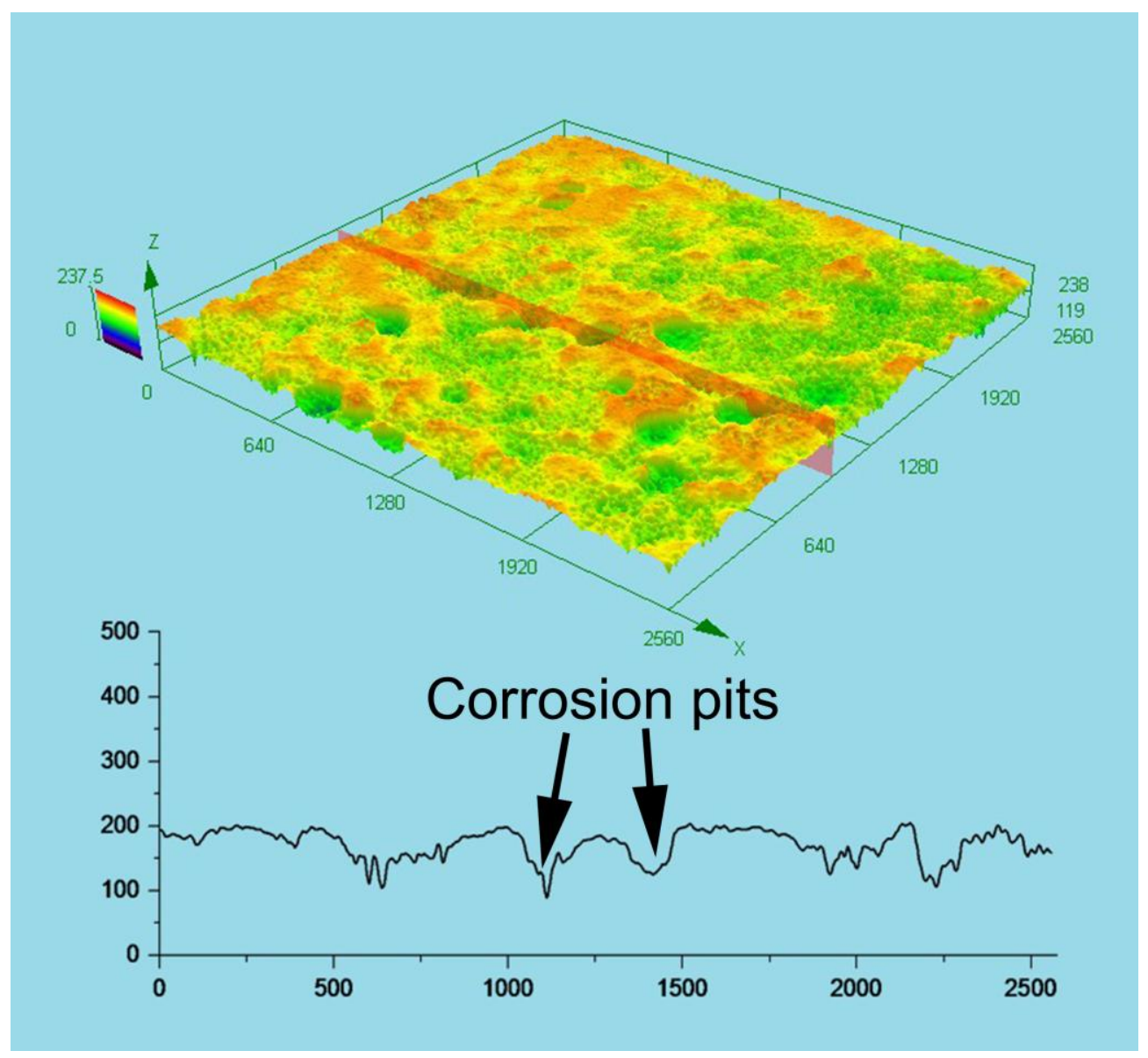

Fig.7. 3-D corrosion profile of as-received material after removing corrosion products 

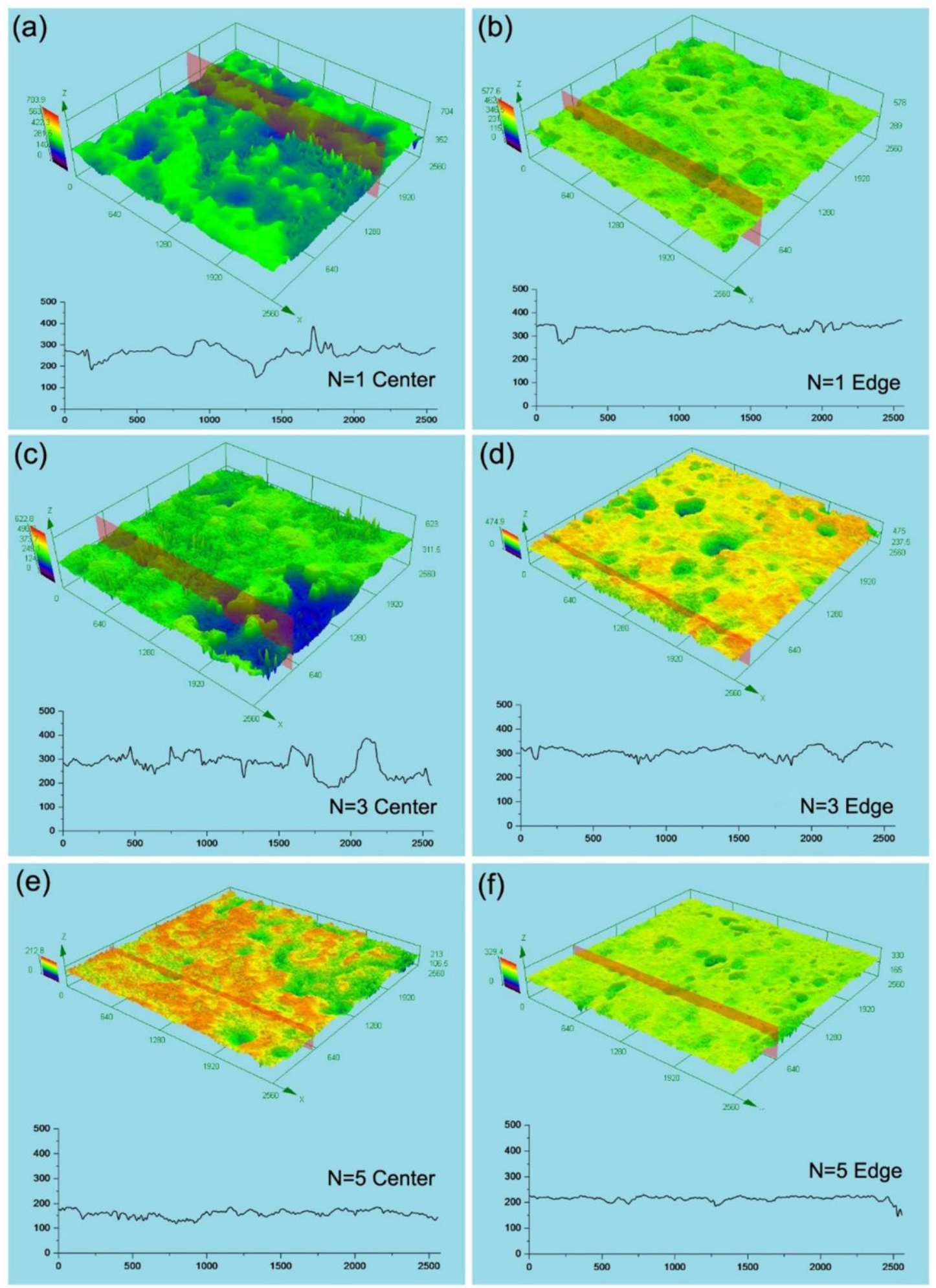

Fig.8. 3-D corrosion profile of HPT material removed corrosion products: (a) $\mathrm{N}=1$, center, (b) $\mathrm{N}=1$, edge,(c) $\mathrm{N}=3$, center,(d) $\mathrm{N}=3$, edge, (e) $\mathrm{N}=5$, center and(f) $\mathrm{N}=5$, edge.

The experimental results show that the degradation behavior of HPT material is different from that of as-received material due to the change of the microstructures. The degradation behavior model of as-received material and HPT material is shown in Fig.9. Before HPT, Mg-Zn-Ca alloy is mainly comprised of $\alpha-\mathrm{Mg}$ and the second phases which distribute along GBs. The corrosion preferentially occurs near the 
second phase particles due to the effect of potential difference between matrix phase and second phase. Meanwhile, GBs are enrichment areas of crystal defects in microstructure, and atoms in these areas are in half-activation state of energy instability. Therefore the atoms in the areas easily divorce from the matrix and severe corrosion pits are formed. The appearance of corrosion pits inevitably leads to the inconsistency of diffusing speed in different directions of corrosion. As a result, a uniform protective layer cannot form in the process of generation and accumulation of corrosion products. Hence, the covering and protecting effect of corrosion product layers on matrix weakens, as well as the loose corrosion products layer cannot prevent the further contact between $\mathrm{Mg}$ matrix and SBF.

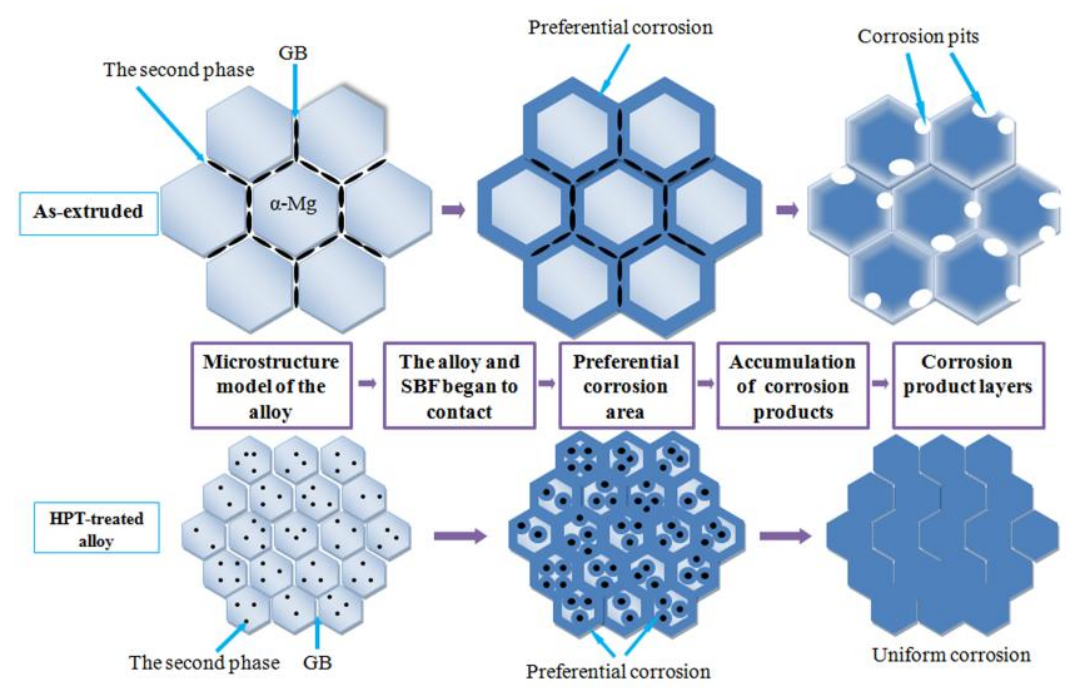

Fig.9 Degradation behavior model of as-received material and HPT material in SBF

The grain size of HPT material after 5 revolutions is extremely small. The grain refinement meant that the density of GBs increases significantly. Some dislocation tangle zone and sub grains may also exist. Meanwhile, the second phase particles tend to distribute dispersedly and uniformly. When HPT material contacts with SBF, galvanic corrosion occurs in the regions near the second phases, which is similar to as-received material. In addition, the regions near GBs, dislocation tangle zones and sub grains also form a certain amount of galvanic corrosion because atoms in GBs, dislocation tangle zones and sub grains are in half-activation state of energy instability. The corrosion preferentially occurs in the regions near second phase particles, GBs, dislocation tangle zones and sub grains simultaneously. The initiation corrosion regions of HPT material increase obviously compared with that of as-received material. The corrosion can diffuse over the whole contact interface between the sample and SBF very soon, and the corrosion rate and degradation degree of the matrix in the adjacent regions tends to be consistent. Fig.10 shows a lot of corrosion holes which distribute uniformly with small diameter on the corrosion interface due to the increase of the initiation corrosion regions. Ultimately, the degradation behavior of HPT material is uniform corrosion in SBF. 

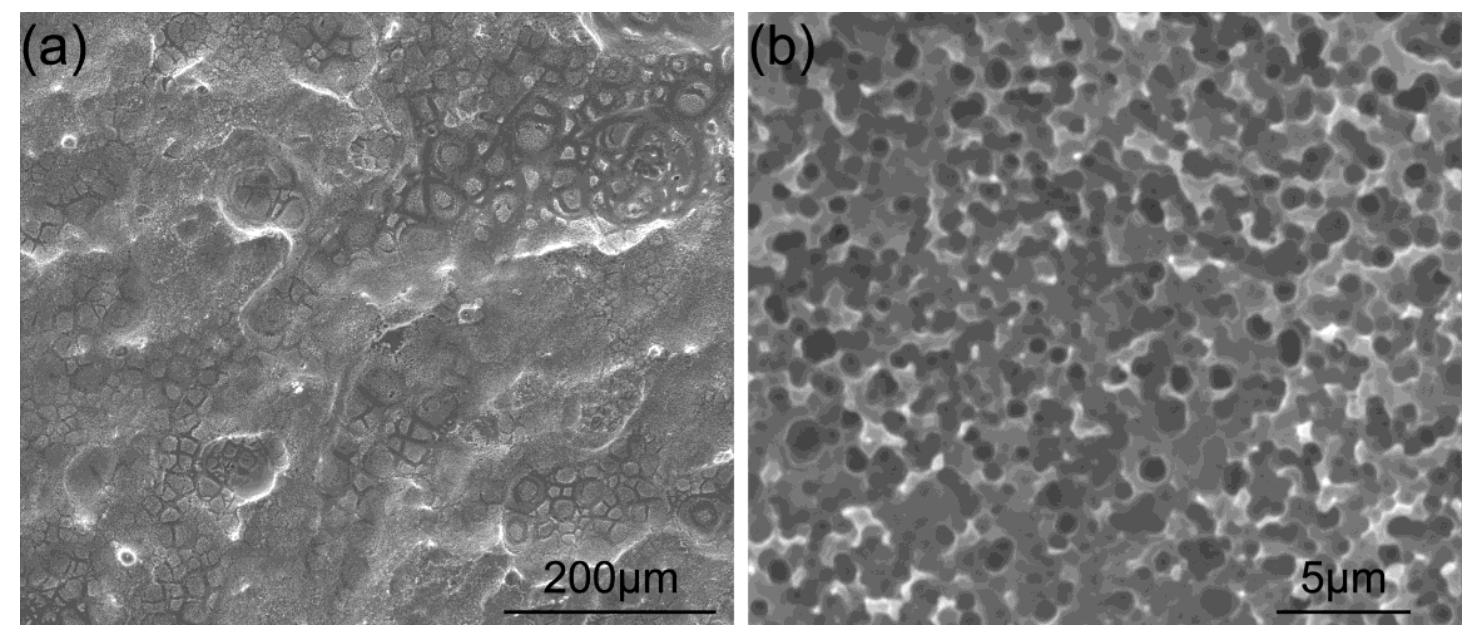

Fig.10. SEM micrograph of corrosion interface of HPT material after 5 revolutions with removed corrosion products immersing in SBF for $48 \mathrm{~h}$.

\section{Conclusion}

In this paper, $\mathrm{Mg}-\mathrm{Zn}-\mathrm{Ca}$ alloy was processed by HPT. The microstructural evolution and corrosion behavior of $\mathrm{Mg}-\mathrm{Zn}-\mathrm{Ca}$ alloy before and after HPT were investigated. The degradation mechanism of HPT material was preliminarily studied, and the results are as follows:

(1) The ultra fine grain could be produced in Mg-Zn-Ca alloy after HPT. The effect of grain refinement became better and the degree of microstructural homogeneity was improved with the increase of HPT revolutions. The average grain size of as-received material was $\sim 11 \mu \mathrm{m}$. However, the homogenous ultra fine grain structure was obtained and the average grain size of HPT material was $\sim 130 \mathrm{~nm}$ when $\mathrm{N}$ increased to 5 revolutions. The second phase mainly distributed along the GBs before HPT, but tended to be dispersive in matrix after HPT. The homogenous UFG alloy could be obtained after the shear strain accumulated to a certain degree

(2) Galvanic corrosion occurred near the GBs in as-received material, and the larger corrosion rate resulted in the formation of corrosion pits. The corrosion resistance of HPT material was improved. The self-corrosion potential showed an anodic shift, and self-corrosion density decreased with the increase of N. After 5 revolutions, the corrosion preferentially occurred in the regions near the UFG boundaries and the second phase particles simultaneously, so the initiation corrosion region covered almost the entire surface of the alloy. As a result, a uniform and compact corrosion product layer formed, and the corrosion interface and profile curves of HPT material showed that the corrosion pits disappeared. The degradation behavior of HPT material showed the typical characteristics of uniform corrosion.

\section{Acknowledgement}

This work was supported by the National Science Foundation of China under Grant No.51171174, the National High Technology Research and Development Program of 
China under Grant Nos.2015AA020301 and 2015AA033603.

\section{Reference}

[1] N.T.Kirkland. Magnesium biomaterials: past, present and future. Corros Eng Sci Techn 2012:47(5): 322-328.

[2] Q.Z.Chen, G.A.Thouas. Metallic implant biomaterials. Mat Sci Eng R 2015:87:1-57.

[3] M.P.Staiger, A.M.Pietak, J.Huadmai, G.Dias. Magnesium and its alloys as orthopedic biomaterials: a review. Biomaterials 2006:27(9):1728-1734.

[4] N.Li, Y.F.Zheng. Novel Magnesium Alloys Developed for Biomedical Application: A Review. J Mater Sci Technol 2013:29(6):489-502.

[5] Y.J.Chen, Z.G.Xu, C.Smith, J.Sankar. Recent advances on the development of magnesium alloys for biodegradable implants. Acta Biomater 2014:10:4561-4573.

[6] L.L.Tan, X.M.Yu, P.Wan, K.Yang. Biodegradable Materials for Bone Repairs: A Review. J Mater Sci Technol 2013:29(6): 503-513.

[7] L.Rennie, C.M.Court-Brown, J.Y.Q.Mok, T.F.Beattie. The epidemiology of fractures in children. Injury 2007:38(8):913-922.

[8] R.Zeng, W.Dietzel, F.Witte, N.Hort, C.Blawert. Progress and challenge for magnesium alloys as biomaterials. Adv Eng Mater 2008:10(8): B3-B14.

[9] Y.F.Ding, C.Wen, P.Hodgson, Y.C.Li. Effects of alloying elements on the corrosion behavior and biocompatibility of biodegradable magnesium alloys: a review. J Materials Chem B 2014:2:1912-1933.

[10] T.Kraus, S.F.Fischerauer, A.C.Hänzi, P.J.Uggowitzer, J.F.Löffler, A.M.Weinberg. Magnesium alloys for temporary implants in osteosynthesis: in vivo studies of their degradation and interaction with bone. Acta Biomater 2012:8(3):1230-1238.

[11] G.S.Wu, J.M.Ibrahim, P.K.Chu. Surface design of biodegradable magnesium alloys - A review. Surf Coat Tech 2013:233(25):2-12.

[12] S.V.Dorozhkin. Biocomposites and hybrid biomaterials based on calcium orthophosphates. Biomatter 2011:1(1): 3-56.

[13] H.Hornberger, S.Virtanen, A.R.Boccaccini. Biomedical coatings on magnesium alloys-a review. Acta Biomater 2012:8(7):2442-2455.

[14] X.N.Gu, Y.F.Zheng, S.P.Zhong, T.F.Xi, J.Q.Wang, W.H.Wang. Corrosion of, and cellular responses to Mg-Zn-Ca bulk metallic glasses. Biomater 2010:31(6):1093-1103.

[15] W.C.Kim, J.G.Kim, J.Y.Lee, H.K.Seol. Influence of $\mathrm{Ca}$ on the corrosion properties of magnesium for biomaterials. Mater Lett 2008:62(25):4146-4148.

[16] M.Alvarez-Lopez, M.D.Pereda, J.A.del Valle, M.Fernandez-Lorenzob, M.C.Garcia-Alonsoa, O.A.Ruanoa, M.L.Escudero. Corrosion behaviour of AZ31 magnesium alloy with different grain sizes in simulated biological fluids. Acta Biomater 2010:6(5):1763-1771.

[17] Q.Wu, S.J.Zhu, L.G.Wang, Q.Liu, G.C.Yue, J.Wang, S.K.Guan. The microstructure and properties of cyclic extrusion compression treated $\mathrm{Mg}-\mathrm{Zn}-\mathrm{Y}-\mathrm{Nd}$ alloy for vascular stent application. J Mech Behav Biomed 2012:8:1-7.

[18] Y.Zhao,H.Z.Guo, M.W.Fu, Y.Q.Ning, Z.K. Yao. Fabrication of bulk ultrafine grained titanium alloy via equal channel angular pressing based thermomechanical treatment. Mater Design 2013:46:889-894. 
[19] F.Salimyanfard, M.R.Toroghinejad, F.Ashrafizadeh, M.Hoseini, J.A.Szpunar. Investigation of texture and mechanical properties of copper processed by new route of equal channel angular pressing. Mater Design 2013:44:374-381.

[20] X.Wang, M.Y.Nie, C.T.Wang, S.C.Wang, N.Gao. Microhardness and corrosion properties of hypoeutectic Al-7Si alloy processed by high-pressure torsion. Mater Design 2015:83:193-202.

[21] R.Z.Valiev, R.K.Islamgaliev, I.V.Alexandrov. Bulk nanostructured materials from severe plastic deformation. Prog Mater Sci 2000:45:103-189.

[22] Y.Liu, X.F.Bian, K.Zhang, C.C.Yang, L.Feng, H.S.Kim, J.Guo. Interfacial microstructures and properties of aluminum alloys/galvanized low-carbon steel under high-pressure torsion. Mater Design 2014:64:287-293.

[23] M.Kai, Z.Horita, T.G.Langdon. Developing grain refinement and superplasticity in a magnesium alloy processed by high-pressure torsion. Mater Sci Eng A 2008:488:117-124.

[24] J.Kratochvíl， M.KruŽík, R.Sedlăček. A model of ultrafine microstructure evolution in materials deformed by high-pressure torsion. Acta Mater 2009:57:739-748.

[25] R.Z.Valiev, T.G.Langdon. Principles of equal-channel angular pressing as a processing tool for grain refinement. Prog Mater Sci 2006:51(7):881-981.

[26] K.Edalati, A.Yamamoto Z.Horita, T.Ishihara. High-pressure torsion of pure magnesium: evolution of mechanical properties, microstructures and hydrogen storage capacity with equivalent strain. Scripta Mater 2011:64(9): 880-883.

[27] I.Dimić, I.Cvijović-Alagić, B.Völker, A.Hohenwarter, R.Pippan, Đ.Veljović, M.Rakin, B.Bugarski. Microstructure and metallic ion release of pure titanium and $\mathrm{Ti}-13 \mathrm{Nb}-13 \mathrm{Zr}$ alloy processed by high pressure torsion. Mater Design 2016:91:340-347.

[28] M.I.A.El Aal, H.S.Kim. Wear properties of high pressure torsion processed ultrafine grained Al-7\%Si alloy. Mater Design 2014:53:373-382.

[29] J.H.Gao, S.K.Guan, Z.W.Ren, Y.F.Sun, S.J.Zhu, B.Wang. Homogeneous corrosion of high pressure torsion treated $\mathrm{Mg}-\mathrm{Zn}-\mathrm{Ca}$ alloy in simulated body fluid. Mater Lett 2011:65:691-693.

[30] Y.H.Xia, B.P.Zhang, Y.Wang. In-vitro cytotoxicity and in-vivo biocompatibility of as-extruded Mg-4.0Zn-0.2Ca alloy. Mater Sci Eng C 2012:32:665-669.

[31] A.P.Zhilyaev, T.G.Langdon. Using high-pressure torsion for metal processing: Fundamentals and applications. Prog Mater Sci 2008:53(6):893-979.

[32] T.Kokubo, H.Takadama. How useful is SBF in predicting in vivo bone bioactivity? Biomaterials 2006:27:2907 - 2915.

[33] N.T. Kirkland, N.Birbilis, M.P.Staiger. Assessing the corrosion of biodegradable magnesium implants: A critical review of current methodologies and their limitations. Acta Biomater 2012:8:925-936.

[34] G.Levi, S.Avraham, A.Zilberov, M.Bamberger. Solidification, solution treatment and age hardening of a Mg-1.6 wt.\% Ca-3.2 wt.\% Zn alloy. Acta Mater 2006:54:523-530.

[35] Y.Z.Du, X.G.Qiao, M.Y.Zheng, K.Wu, S.W.Xu. Development of high-strength, low-cost wrought $\mathrm{Mg}-2.5$ mass\% $\mathrm{Zn}$ alloy through micro-alloying with $\mathrm{Ca}$ and La. Mater Design 2015:85:549-557.

[36] L.B. Tong, M.Y. Zheng, L.R. Cheng, D.P. Zhang, S. Kamado, J. Meng, H.J. Zhang. Influence of deformation rate on microstructure, texture and mechanical properties of indirect-extruded 
Mg-Zn-Ca alloy. Mater Charact 2015:104:66-72.

[37] Y.Lu, A.R.Bradshaw, Y.L.Chiu, I.P.Jones. Effects of secondary phase and grain size on the corrosion of biodegradable Mg-Zn-Ca alloys. Mat Sci Eng C 2015:48:480-486.

[38] X.Gso, J.F.Nie. Characterization of strengthening precipitate phases in a $\mathrm{Mg}-\mathrm{Zn}$ alloy. Scripta Mater 2007:56:645-648.

[39] J.B.Clark. Transmission electron microscopy study of age hardening in a Mg-5 wt.\% Zn alloy. Acta Metall 1965: 13(12):1281-1289.

[40] F.A.Mohamed, S.S.Dheda. On the minimum grain size obtainable by high-pressure torsion. Mater Sci Eng A 2012:558: 59-63. 